[Aus dem Institut für Infectionskrankheiten in Berlin.]

(Director: Geh. Med.-Rath Prof. Dr. R. Koch.)

\title{
Ueber das Hünermann'sche Verfahren der Wasser- desinfection nebst Bemerkungen über die bei der Prüfung derartiger Desinfectionsmittel anzuwendenden Untersuchungsmethoden.
}

$$
\text { Von }
$$

Stabsarzt Dr. Schüder.

Das Bestreben, ein als möglicher Weise gesundheitssehädlich anzusehendes Wasser durch Zusatz chemischer Mittel für den Genuss brauchbar zu machen, ist schon sehr alt. So erwähnt Kaufmann ${ }^{1}$, dass die ägyptischen Fellachen das Wasser des Nils schon seit Jahrhunderten trinkbar machen durch Filtration und. Sedimentirung, die, abgesehen von der in neuerer Zeit gebrauchten Alaunlösung durch zerstossene Pfirsichkerne bewirkt wurde. - Der Zusatz chemischer Mittel soll entweder in dem zu reinigenden Wasser einen Niederschlag hervorrufen, welcher die organischen Fremdkörper und Bakterien mit niederreisst, oder die im Wasser enthaltenen Keime direct vernichten.

Die Zahl der im Laufe der Zeit zu diesen Zwecken angegebenen Mittel ist eine ausserordentlich grosse. Sch u m b u rg ${ }^{2}$ hat von einer Reihe von Jahren im Auftrage der Medicinalabtheilung des Königl. Preuss. Kriegsministeriums allein über 20 derartiger, für die Wasserdesinfection angegebener Mittel geprüft mit fast ausschliesslich ungünstigem Ergebniss. Einzelne Mittel liessen gar keine, einzelne nur geringe Wirkung erkennen, andere brauchten sehr

${ }^{1}$ 68. Versammlung deutscher Naturforscher und Aerzte in Frankfurta/M., 21. bis 26. September 1896. (Citirt nach Sehumburg.)

${ }^{2}$ Veröffentlichungen auf dem Gebiete des Militär-Sanitätswesens, Hfț. 15. S. $34 \mathrm{ff}$. 
lange Zeit zur Entfaltung ihrer Wirksamkeit, so z. B. das von Kröhnke ${ }^{1}$ angegebene Kupferchlorür und das namentlich von Altehöfer ${ }^{2}$ empfohlene Wasserstoffsuperoxyd, welche 24 Stunden einwirken müssen; noch andere machten durch die grossen benöthigten Mengen das Wasser zum Genuss unbrauchbar, wie z. B. der Kalk, der nach Liborius ${ }^{3}$ in einer Menge von $246 \mathrm{mg}$ pro Liter und nach $\mathrm{Pfuhl}^{4}$ in einer Concentration von 10 procentigem Kalkhydrat dem Wasser zugesetzt werden muss. -

Nun muss mar aber von einem für die Trinkwasserdesinfection praktisch brauchbaren Mittel verlangen, dass es nicht nur sicher keimvernichtend, sondern auch möglichst schnell wirkt, leicht zu handhaben, nicht zn kostspielig ist, auch in grösseren Mengen mit dem Wasser genossen, nicht die Gesundheit schädigt, sowie das Wasser in Bezug auf Aussehen, Geruch und Geschmack nicht allzu sehr verändert.

Je mehr diesen Gesichtspunkten Rechnung getragen wurde - und das ist eigentlich bei allen neueren Untersuchungen der Fall gewesen desto mehr verengte sich der Kreis dur überhaupt für praktische Zwecke in Betracht kommenden Mittel für die chemische Desinfection des Trinkwassers und man kann behaupten, dass neuerdings eigentlich nur noch das Chlor und das Brom in Betracht kamen und in den Bereich der Untersuchungen gezogen sind,

Was zunächst das Chlor anlangt, so hat schon R. Koch in seiner grossen, in den Mittheilungen aus dem Reichsgesundheitsamt enthaltenen Desinfectionsarbeit ${ }^{5}$ auf die grosse baktericide Kraft der Chlorverbindungen hingewiesen und in einer Reihe von Arbeiten von Behring ${ }^{6}$, Sternberg ${ }^{7}$, Jäger ${ }^{8}$, Liborius ${ }^{9}$, Kitasato ${ }^{10}$, v. Esmareh ${ }^{11}$, Pfuhl ${ }^{12}$, Nissen ${ }^{13}$ sind diese Angaben bestätigt und erweitert. Im Jahre 1893 lenkte M. Traube ${ }^{14}$

1 Journal für Gasbeleuchtung und Wasserversorgung. 10. Septbr. 1893.

2 Centralblatt für Bakteriologie. Bd. VIII. S. 129.

${ }^{3}$ Diese Zeitschrift. Bd. II. S. $15 \mathrm{ff}$.

4 Ebenda. Bd. XII. S. 509.

${ }^{5}$ Mittheilungen aus dem Kaiserl. Gesundheitsamte. Bd. I. S.199ff.

6 Ueber Desinfection, Desinfectionsmittel u. Desinfectionsmethoden. Behring's Gesammelte Abhandlungen. 1893. S. 311.

' Preliminary Report mate by the Committee of Desinfectants of the American Public Health Association. - Ref. Uffelmann's Deutsche Vierteljahresschrift für öfentl. Gesundheitspflege. 1886. Bd. XVIII. Suppl. S. 155.

${ }^{8}$ Arbeiten aus dem Kaiserl. Gesundheitsamte. Bd. V. S. $247 \mathrm{fl}^{2}$.

${ }^{9}$ Diese Zeitschrift. Bd. II. S. 15 ff.

10 Ebenda. Bd. III. S. $404 \mathrm{ff}$.

11 Ebenda. Bd. V. S.67ff.

12 Ebenda. Bd. VI. S. $97 \mathrm{ff}$.

${ }^{13}$ Ebenda. Bd. VIII. S. $62 \mathrm{ff}$.

${ }^{14}$ Ebenda. Bd. XVI. S. $149 \mathrm{ff}$. 
zuerst die Aufmerksamkeit auf die Verwendung des Chlorkalks als Trinkwasserreinigungsmittel. Traube nahm sehr geringe Mengen $(4.26 \mathrm{mg})$ Chlorkalk, enthaltend $1.065^{\mathrm{mg}}$ wirksames Chlor auf den Liter and innerbalb von 2 Stunden, oder auch schon in kürzerer Zeit, sollten alle Mikroorganismen abgetödtet sein. Zur Entfernung des überschüssigen Chlorkalks genügte ein Zusatz von $2.09 \mathrm{mg}$ Natriumsulfit. Traube arbeitete allerdings nicht mit pathogenen Keimen, sondern mit Bakterien aus faulender Fleischflüssigkeit. 1894 bestätigte Karlinski ${ }^{1}$, dass 1 mg freies Chlor pro Liter Wasser zur Abtödtung aller Wasserbakterien, Cholera-und Typhusbacillen genügt, und dass bei der Combination des Chlors mit einem chemisehen Filterverfahren grobe Verunreinigungen enthaltende und inficirte Wässer so gereinigt werden könnten, dass sie die strengsten Anforderungen an Gefahrlosigkeit und Appetitlichkeit erfüllten. Des Weiteren bestätigte Kratschmer ${ }^{2} 1894$ durch seine Versuche, dass ${ }^{m g}$ Chlor auf 1 Liter Wasser sogar Milzbrandsporen abtödtete.

Lode ${ }^{3}$ und auch Bassenge haben 1895 das Traube'sche Verfahren geprüft und weiter auszubilden versucht. Lode zog auch Bacterium coli, Typhus, Cholera, Milizbrand, sowie künstlich und natürlich verunreinigtes Wasser in den Bereich seiner Versuche und fand, dass die von Traube angewandte Menge von $1^{\mathrm{mg}}$ freien Chlors auf 1 Liter Wasser in kürzerer Zeit unzulänglich wirkt und ebenso auch noch nach 24 Stunden. Er erhöhte die 'l'raube'sche Chlormenge um das 30 fache, also auf $30 \mathrm{mg}$ pro Liter und kürzte dafür die Einwirkungsdauer bis auf 10 Minuten ab, was einen grossen praktischen Gewinn bedeutete. Zur: Bindung des unverbrauchten Chlors diente Calcium- oder Natriumsulfit. Lode wies gleichzeitig auf die mit der Zeit auftretende Werthverminderung des Chlorkalks und seine schwere Benetzbarkeit hin. Letzteren Uebelstand suchte er durch feines Verreiben in Wasser auf mechanischem Wege, wie auch durch Zersetzung des Chlorkalks mittels $0.25 \mathrm{grm}$ Citronensäure pro liter auf chemischem Wege abzuhelfen. Lode erhielt allerdings kein klares Wasser, sondern ein durch Flocken von kohlensaurem Kalk getrübtes und glaubt aus diesem Grunde eine nachträgliche Filtration in Aussicht zu nehmen, bezw. einen Zusatz von Salzsäure machen zu müssen. Bassenge gelangte ebenfalls zu einer günstigen Beurtheilung des Traube'schen Princips.

1 Versammlung dectscher Naturforscher und Aerzte in Wien am 26. September 1894. Wiener klin. Wochenschrift. 1894. S. 915. Congressbericht.

${ }^{2}$ Nach Schumburg: Veröffentlichungen aus dem Gebiete des Militär-Sanitätswesens. Hft. 18. S. 79.

${ }^{9}$ Archiv für Hygiene. Bd. XXIV. S. $236 \mathrm{ff}$.

4 Diese Zeitschrift. Bd. XX. S. $227 \mathrm{ff}$. 
Nach seinen Versuchen genügte ein Zusatz von $0.0978 \mathrm{grm}$ activen Chlors, entsprechend $0.15 \mathrm{grm}$ käuflichen Chlorkalks a uf 1 Liter Wasser, um binnen 10 Min. sehr stark mit pathogenen Keimen verunreinigtes Wasser sicher keimfrei zu machen. Bei längerer Einwirkungsdauer, z. B. 2 Stunden, vermindert sich die nöthige Chlormenge auf $0.0108 \mathrm{grm}$. Das nicht verbrauchte Chlor macht Bassenge durch Calciumbisulfịt ( $3^{\mathrm{cem}}$ einer gesättigten Lösung $=0.02 \mathrm{grm}$ freien Chlors) unschädlich, wodurch eine geringe Menge schwefelsauren Kalbs als Niederschlag ausgefällt wird. Bassenge erachtet sein Verfahren als vollkommen sicher, um auf chemischem Wege sicher keimfreies Wasser herzustellen. Schumburg ${ }^{1}$ hat 1897 auf Grund seiner Versuche das von Traube ersonnene und besonders von Bassenge ausgebildete Verfahren in seiner Wirkung als richtig und zuverlässig anerkannt und auch Löffler ${ }^{2}$ sagt in dem W eyl'schen Handbuch für Hygiene, dass sich das Traube'sche Princip als überaus werthvoll für die Praxis erwiesen habe. Ballner ${ }^{3}$ bestätigt in einer Arbeit aus diesem Jahre, dass das Chlorkalkverfahren als gen ügend zuverlässig anzusehen sei.

Für das Brom hat $1894 \mathrm{Kratsehmer}^{4}$ eine dem Chlor äbnliche keimvernichtende Wirkung nachgewiesen, dann ist es 1896 gleichzeitig von Jaworowski ${ }^{5}$ und Schumburg ${ }^{6}$ zur Wasserdesinfection angewandt. Jaworowski setzte dem zu reinigenden Wasser soviel gesättigtes Bromwasser zu, dass es nach $1 / 2$ Stunde noch Bromgeruch aufweist. Das Brom wird dann mit basischem Wismuthsulfit und Wismuthoxydul beseitigt. Das Verfahren ist nach Schumburg ${ }^{7}$ gänzlich unbrauchbar, weil sich bei der Nachprüfung die entstandene braune, schlammige Trübung nach 24 Stunden noch nicht abgesetzt hatte. Schumburg war auf das Brom verfallen, einmal der dem Verfahren mit Chlorkalk selbst, sowie des Weiteren der Entfernung des überschüssigen Chlors anhaftenden Sehwierigkeiten halber, andererseits weil Brom bei gewöhnlichem Druck bereits eine Flüssigkeit ist. Schumburg bildete sein Verfabren dahin aus, dass nach seinen Angaben ${ }^{8}$ mit 0.06 orm freien Broms auf 1 Liter Wasser in 5 Minuten fast sämmtliche Wasserbakterien und sämmtliche bisher im Wasser nachgewiesenen pathogenen Keime sicher abgetödtet werden

1 Veröffentlichungen aus dem Gebiete des Militär-Sanitätswesens. Hft. 15. S.83.

2 Jena 1896. S. 709.

3 Wiener med. Wochenschrift. 1901. Nr. 31, 33.

4 Wiener klin. Wochenschrift. 1894. S. 915.

${ }^{5}$ Ref. Pharmacentische Centralhalle. Bd. XXXVII. Nr. 51.

${ }^{6}$ Veröffentlichıngen aus dem Grebiete des Militär-Sanitätswesens. Hft. 15. S.86.

7 Ebenda. S. 85.

${ }^{8}$ Deutsche med. Wochenschrift. 1897. Nr.10 u. 25. - Deutsche militärärztl. Zeitschrift. 1897. S. $289 \mathrm{ff}$. 
können. Das Brom wird von ihm in Form einer Brom-Bromkalilösung angewandt, von der $0.2 \mathrm{cem} 0.06 \mathrm{grm}$ freies Brom enthalten. Das überschüssige Brom wird mit Natrium sulfurosum und Natrium carbonicum siccum $(0.095+0.94)$ unschädlich gemacht. Teber den Werth des Schumburg'schen Verfahrens äusserte sich zunächst 1900 A. Pfuhl ${ }^{1}$ auf Grund seiner umfangreichen Nachprüfungen in sehr lobender Weise and stellt dasselbe unter den analogen Verfahren an die erste Stelle. Desgleichen äussert sich Ballner ${ }^{2} 1901$ dahin, dass das Bromverfahren in seiner sterilisirenden Wirkung als genügend zuverlässig anzusehen sei.

Schon ehe die Nachtheile in der Anwendung des Chlorkalks zur Wasserdesinfection Schumburg auf die Anwendung des Broms gebracht hatten, waren es 1894 Sickenberger und Kaufmann ${ }^{3}$ gewesen, welche an Stelle des Chlorkalks das unterchlorigsaure Natrium setzten und mit demselben Nilwasser sterilisirten. Sie wollen bei Zusatz von $5^{\mathrm{mg}}$ reinen Chlors auf 1 Liter Wasser Vernichtung sämmtlicher Keime erzielt haben. Im Sommer d. J. haben nun Hünermann und Deiter ${ }^{4}$ ein Verfahren der Trinkwasserdesinfection mit Natriumhypochlorit erprobt und für durchaus brauchbar befunden, zugleich auch eine Lösung von Natriumhypochlorit mit einfachen Mitteln hergestellt, welche einen constanten Chlorgehalt ziemlich lange behält, wodurch das Verfahren an Billigkeit und Bequemlichkeit der Handhabung sehr gewiunt. Hünermann setzt von seiner $\mathrm{NaO}$ 0l-Lösung soviel zum Wasser, dass auf den Liter 0.04 grm wirksames Chlor kommen, d. h. also $0.4^{\mathrm{eem}}$ einer 10 procent. Lösung. Eine Ein wirkungsdauer ron 10 Minuten soll genügen, um alle im Wasser enthaltenen Typhus- und Colibacillen sowie Choleravibrionen mit Sicherheit abzutödten. Der Härtegrad und der Gehalt an organischer Substanz sollen die Desinfection nicht erbeblich beeinträch-

ige Die Bindung des Chlors erfolgt nach vollendeter Desinfection mittels einer Lösung von. Natriumsulfat $\left(\mathrm{Na}_{2} \mathrm{SO}_{3}\right)$, von welchem $0.14 \mathrm{grm}$ für $0.04^{\mathrm{grm}}$ Chlor genügen. Eine Gesundheitsschädigung durch die angewandten Chemicalien soll nicht zu befürchten sein.

Nach dem Vorstehenden konnte es scheinen, als ob wir in dem Chlor in der Form des Chlorkalks oder unterchlorigsauren Natriums, bezw. im Brom in der Schumburg'schen Brom-Bromkalilösung geeignete Mittel zur Desinfection des Trinkwassers

${ }^{1}$ Diese Zeitschrift. 1900. Bd. XXXIII. S. $53 \mathrm{ff}$.

2 Wiener med. Wochenschrift. 1901. Nr. 31-33.

${ }^{3}$ Le Progrès. Journal Quotidien paraissant au Caire. 13. December 1894. (Citirt nach Bassenge.)

4 Deutsche med. Wochenschrift. 1901. Nr. 24. S. 391 u. 392. 
besässen, welche allen an dieselben zu stellenden Anforderungen genügten. So segensreich dies auch sein würde in Wirklichkeit scheint es nicht der Fall zu sein.

Schon bei meiner Prüfung des Schumburg'schen Verfahrens ${ }^{1}$ bin ich mit den Resultaten dieses Autors, sowie mit denen A. Pfuhl's in völligen Gegensatz gekommen, und, um es vorweg zu bemerken, bei der Prüfung des Hünermann'schen Verfahrens ist es mir nicht viel anders gegangen. Nach Abschluss meiner Versuche ersah ich aus einer im November d. J. erschienenen Arbeit von Rabs ${ }^{2}$ über Trinkwasserdesinfection mittels Chlor, dass derselbe zunächst die von Lode mit Chlorkalk und Hủnermann mit Natriumhypochloroit gemachten günstigen Erfahrungen vollständig bestätigt ${ }^{3}$, dass aber die Resultate mit dem Hünermann'schen Verfahren gegenũber Choleravibrionen sofort ganz andere wurden, sobald er statt der bisher üblichen Prüfungsmethoden auf die von mir s. Z. angegebene Weise ${ }^{4}$ untersuchte.

Ich glaube nicht zu weit zu gehen, wenn ich auf Grund der im Nachstehenden niedergelegten Beobachtungen die Befürchtung ausspreche, dass ausser dem Hünermann'schen auch die übrigen Verfahren der Trinkwasserdesinfection mittels Chlor zunächst noch als unzuverlässig in der sicheren Keimvernichtung anzusehen sind und eine wirklich praktische Bedeutung erst erlangen können, wenn sie eine Nachprüfung nach den am Schlusse von mir angegebenen Methoden bestehen würden. Die so günstigen bisherigen Resultate anderer Untersucher sind, wie ich vermuthe, durch die Unzulänglichkeit der angewendeten Untersuchungsmethoden vorgetäuscht. Zwei Fehler sind gemacht; einer vou allen Untersuchern, dass sie viel zu kleine Mengen des inficirten und dann desinficirten Wassers auf entwickelungsfähig gebliebene Keime untersuchten, der zweite, dass eine Anzahl Untersucher zum Nachweis der lebensfähig gebliebenen Keime ausschliesslich mit festen Nährböden arbeitete.

Die Prüfung des Hünermann'schen Verfahrens gestaltete sich nun folgendermaassen.

Es wurde die vom Autor übersandte Chlorlösung (10 Procent $\mathrm{NaOCl}$ ) zu den Versuchen verwandt, nachdem jedes Mal vor ihrer Benützung der Chlorgehalt im chemischen Laboratorium festgestellt war. Zur Entfernung

1 Diese Zeitschrift. Bd. XXXVII. S. $307 \mathrm{ff}$.

"Hygienische Rundschau. 1901. Nr. 22. S. 1085.

${ }^{3}$ Ebenda. S. 1086.

${ }^{4}$ Diese Zeitschrift. Bd. XXXVII. S. 312 u. 313. 
des Chlors, nachdem dasselbe seine Wirkung gethan, wurde eine im chemischen Laboratorium hergestellte schwefligsaure Natriumlösung $\left(\mathrm{Na}_{2} \mathrm{SO}_{3}\right)$ benutzt. Bei jedem einzelnen Versuch wurde mittels Jodzinkstärkelösung festgestellt, ob etwa noch freies Chlor, welches auf die Platten mit übertragen eine Beeinträchtigung des Wachsthums herbeiführen könnte, vorhanden war. Zutreffendenfalls wurde dasselbe durch Hinzufügen weiterer schwefligsaurer Natriumlösung beseitigt.

Sämmtliche Versuche würden in gut verschliessbaren Glasgefässen angestellt, um einmal durch fleissiges Umschütteln während des Versuches eine gründliche Mischung des Chlors mit allen Theilen des zum Versuch dienenden Wassers zu erreichen, andererseits um ein Entweichen des Chlors noch während des Versuches zu verhindern. Allerdings wurden so für den Versuch etwas günstigere Bedingungen geschaffen, als dies bei der Anwendung des Verfahrens in der Praxis in den meisten Fällen wohl der Fall sein wird.

$\mathrm{Zu}$ den Versuchen wurde Wasser verschiedener Herkunft benutzt. Es wurde auf verschieden grosse Härte und wechselnden Gehalt an organischen Substanzen Werth gelegt, und so diente

1. destillirtes Wasser,

2. Brunnenwasser,

3. Wasser der hiesigen Wasserleitung.

4. Wasser aus dem Spandauer Schifffahrtscanal, den Versuchszwecken.

Die keimvernichtende Kraft des Chlors wurde wie s. Z. die des Broms ${ }^{1}$ in mehreren Versuchsreihen von mir festzustellen versucht, und zwar

1. in Wasser verschiedener Art obne Zusatz pathogener Keime,

2. nach Zusatz von Choleravibrionen,

3. nach Zusatz von Typhusbacillen,

4. nach Zusatz von Ruhrbacillen.

Von den drei letzteren wurden stets 24 Stunden alte auf Agar bei $37^{\circ}$ gewachsene Culturen benutzt. Die Culturen wurden sehr sorgfältig aufgeschwemmt und dann in dem zu inficirenden Wasser durch längeres, kräftjges Umschütteln so fein vertheilt, dass höchst selten nur noch feinste Partikelchen mit blossem Auge in dem Wasser wahrnehmbar waren. Im Allgemeinen wurde mit Zusatz geringerer Mengen pathogener Keime, als s. Z. bei der Prüfung des Schumburg'schen Verfahrens gearbeitet. Von einer Filtration der Aufschwemmungen wurde mit Ausnahme einiger Ver-

1 Das Schumburg'sche Verfahren der Wasserreinigung inittels Brom. Diese Zeitschrift. Bd. XXXVII. S. $307 \mathrm{ff}$.

Zeitschr, f. IIyglene, XXxI. 
suche zu besonderem Zwecke aus den früher bei Prüfung des Schumburg'schen Bromverfahrens aus ejnander gesetzten Gründen ${ }^{1}$ abgesehen.

Die nach Einwirkung des unterchlorigsauren Natrium zuzusetzende Lösung von schwefligsaurem Natrium wurde vor dem Gebrauch nicht sterilisirt, da wiederholt vorgenommene Plattenversuche ergaben, dass die Lösung sich keimfrei erhielt. Bei Anwendung steriler Pipetten war also nicht zu befürchten, dass dem zu den Versuchen dienenden Wasser noch nachträglich entwickelungsfähige Keime zugesetzt würden.

Die Mehrzahl der Versuche wurde wiederholt, der Controle halber. In den die Zusammenstellung der Versuche enthaltenden Tabellen sind die Wiederholungen der Versuche durch den der laufenden Nummer beigefügten Buchstaben a kenntlich gemacht.

I Diese Zeitschrift. Bd. XXXVII. S. 317 u. 318: „Mit solchen Verhältnissen wie bei den durch doppelte Filter filtrirten Aufschwemmungen, wo gewissermaassen die einzelnen Keime im Wasser schwebend dem Angriff des Broms ausgesetzt sind, wird in der Praxis selten zu rechnen sein. Es mag dies vielleicht vorkommen, wenn Wasser durch typhusbacillenhaltigen Harn verunreinigt ist, oder in einem Wasser eine grosse Vermehrung pathogener Keime an einzelnen Stellen stattgefunden hat. Bei den hauptsächlich im Wasser in Betracht kommenden pathogenen Keimen der Cholera, des Typhus, der Dysenterie geschieht die Infection des Wassers hauptsächlich durch Darmansleerungen, und in diesen befinden sich, wenn dieselben auch in Flüssen oder Gewässern stark verdünnt werden, die einzelnen Keime nicht immer so isolirt wie in einer filtrirten Culturaufschwemmung.

Aus diesen Gründen würde selbst der Nachweis, dass das Bromverfahren die pathogenen Keime in filtrirten Cultaraufschwemmungen sicher vernichtet, noch nicht dafür beweiskräftig sein, dass dasselbe in auf natürliche Weise verunreinigtem Wasser der Fall ist.“

„A Asserdem habe ich bei meinen Untersuchungen gefunden, dass bei sorgfältiger Aufschwemmung von 24 Stunden alten Choleraculturen und nach längerem, kräftigeru Unschütteln dieser Aufschwemmung in dem zu inficirenden Kolben mit Wasser höchst selten mit blossem Auge noch erkennbare Partikelchen sich finden, und bei den Versuchen mit Typhus war dies überhaupt niemals der Fall." Und ferner:

„Ehe ich diese Versuche sammt den Ergebnissen auch in einer kleinen Tabelle zusammenstelle, möchte ich noch auf die weitere Schlussfolgerung Schumburg's aus seinem zuletzt erwähnten Versuch zurücklommen, dass man nämlich, wie schon andere Untersucher angegeben haben, zu Desinfectionszwecken zu benutzende Bakterienaufschwemmung filtriren soll. Ich meine, das Gegentheil ist richtig, denn wenn man den Werth eines Desinfectionsmittels erfahren will, soll man demselben die zu veruichtenden Bakterien nicht unter Umaständen, wie dieselben am leichtesten zu vernichten sind, gegenüberstellen, sondern mindestens so, wie sie in der Praxis zu vernichten sind, nämlich in den verschiedenen Absonderungen der Erkrankten, oder eher noch unter erschwerten Umständen. Erst dann wird man, sich über den Werth eines Desinfectionsmittels für die Praxis nicht täuschen." 
1.

Die crste Versuchsreihe erstreclite sich auf die Versuche, Wasser von verschieden grossem Keimgehalt rou diesen Keimen mittels des Verfahrens zu befreien. Zur Ermittelung des Keimgehaltes diente vor und nach Anwendung des Chlorverfahrens das gewöhnliche Gelatineplattenverfahren. Während bei der Feststellung des Keimgehaltes vor dem Versuch je $1 \mathrm{~cm}$ Wasser oder ein Theil davon benutzt wurde, dienten nach dem Versuch je $10^{\mathrm{ccm}}$ in grossen Platten dazu, um reniger ron Zufälligkeiten abhängig zu sein. Bei einem Vergleich der Zahlen in den beiden letzten Spalten der Tabelle I sind daher, um das richtige Reductionsrerbältniss der Keimgehaltszahlen zu erhalten, die Zahlen in der vorletzten Spalte zehnmal grösser zu nehmen. Bei dem Versuch 5 sowie 5 a wurde ein destillirtes Wasser genommen, welches schon länger im Laboratorium (in geschlossener Flasche) gestanden hatte, um recht viel Keime in demselben zu haben.

Tabelle I.

\begin{tabular}{|c|c|c|c|c|c|c|}
\hline $\begin{array}{l}\dot{2} \\
\dot{z} \\
\dot{H}\end{array}$ & $\begin{array}{c}\text { Art } \\
\text { des Wassers }\end{array}$ & $\begin{array}{c}\text { Versuchs- } \\
\text { menge } \\
\text { l.iter }\end{array}$ & $\begin{array}{c}\text { Menge der } \\
\text { zugesetzten } \\
10 \text { procentigen } \\
\text { Hün er- } \\
\text { maun'schen } \\
\text { Lösung in ccm }\end{array}$ & $\begin{array}{c}\text { Ein- } \\
\text { wirkungs- } \\
\text { dauer } \\
\text { Minuten }\end{array}$ & $\begin{array}{l}\text { Keimzabl } \\
\text { des Wassers } \\
\text { iv } 1 \text { ccm } \\
\text { vor dem } \\
\text { Versuche }\end{array}$ & $\begin{array}{l}\text { Keimzahl } \\
\text { des Wassers } \\
\text { in } 10 \text { cem } \\
\text { nach dem } \\
\text { Versuche }\end{array}$ \\
\hline 1 & destillirtes & 1 & 0.4 & 10 & 224 & 1 \\
\hline $1 \mathrm{a}$ & , & 1 & 0.4 & 10 & $2 \div 4$ & 12 \\
\hline 2 & Iseitung & 1 & $0 \cdot 4$ & 10 & 45 & 0 \\
\hline $2 a$ & $"$ & 1 & 0.4 & 10 & 45 & 1 \\
\hline 3 & Brumnen & 1 & $0 \cdot 4$ & 10 & 885 & 4 \\
\hline $3 a$ & " & 1 & $0 \cdot 4$ & 10 & 885 & 0 \\
\hline 4 & Canal & 1 & $0 \cdot 4$ & 10 & 487000 & 21 \\
\hline $4 \mathrm{a}$ & ", & 1 & 0.4 & 10 & 487000 & 18 \\
\hline 5 & destillirtes & 1 & 0.4 & 10 & 23400 & 0 \\
\hline $5 \mathrm{a}$ & ", & 1 & 0.4 & 10 & 23400 & 0 \\
\hline 6 & Jeitung & 1 & $0 \cdot 4$ & 10 & 48 & 0 \\
\hline $6 \mathrm{a}$ & ," & 1 & $0 \cdot 4$ & 10 & 48 & 0 \\
\hline 7 & Bramen & 1 & $0 \cdot 4$ & 10 & 870 & 0 \\
\hline $7 \mathrm{a}$ & , & 1 & $0 \cdot 4$ & 10 & 870 & 0 \\
\hline 8 & Canal & 1 & 0.4 & 10 & $3938: 0$ & 2 \\
\hline $8 a$ & ", & 1 & 0.4 & 10 & 393800 & 1 \\
\hline
\end{tabular}

Aus dieser Tabelle ergiebt sich, dass der Hünermann'schen Lösung eine ganz bedeutende keimvernichtende Wirkung inne wohnt. Unter 16 Fällen gelang es acht Mal in je $10^{\mathrm{ccm}}$ des bebaudelten Wassers beine auf Gelatine entwickelungsfähigen 
Keime mehr nachzuweisen, während das Wasser vorher bis 234000 Keime in $10 \mathrm{cem}$ enthalten hatte. $0 \mathrm{~b}$ das Wasser wirklich völlig keimfrei war, hätte sich nur entscheiden lassen, wenn die ganze zum Versuch benutzte Menge durchsucht wäre, was mittels Plattenverfahrens ziemlich umständlich gewesen, aber nach Analogie der Versuche mit Cholera, Typhus und Ruhr mittels Anreicherungsverfahrens nach Zusatz concentrirter, steriler Peptonlösung und Aufenthalt bei $22^{\circ}$ durchzuführen gewesen wäre. - In den übrigen acht Versuchen, in denen die Platten nicht völlig steril blieben, ist jedenfalls auch eine so erhebliche Reduction der Keimzahl eingetreten (z. B. von 4870000 auf 21 bezw. 18 and 3938000 auf 2 bezw. 1), dass sie einer völligen Sterilisirung fast gleich zu achten ist, denn eine Abtödtung der im Wasser zuweilen vorhandenen sporenbildenden Bakterien ist billiger Weise nicht zu verlangen.

\section{2.}

In der nun folgenden Versuchsreihe wurde die keimvernichtende Kraft der Hünermann'schen Lösung auf Choleravibrionen in den gleichen Wasserarten erprobt. Von den frisch auf Agar 24 Stunden bei $37^{\circ}$ gewachsenen Culturen wurden verschieden grosse Mengen: $1 / 2,1 / 4$ Cultur und je 3 und 1 Oese von Aufschwemmungen (1. Agarcultur in $10 \mathrm{~cm}$ Wasser) dem zu untersuchenden Wasser zugesetzt. Das weitere Verfahren gestaltete sich genau so wie s. Z. bei den gleichen Untersuchungen mit der Schumburg'schen Brömlosung. ${ }^{x}$

Die Resultate dieser Versuchsreihe enthält die folgende Tabelle II.

1 Diese Zeitschrift. Bd. XXXVII. S. 312: „Zum Nachweis der im bromirten Wasser etwa noch lebend gebliebenen Vibrionen wurde das Pepton-Anreicherungsverfahren und die Cholerarothreaction beautzt. Anfangs wurden nebenher auch noch Gelatineplatten angelegt (Versuch 1 bis 12 der Tabelle II). Die angewandte Untersuchungsmethode erlaubte das ganze bromirte Wasser a ach lebend gebliebenen Choleravibrionen abzusuchen, und hierauf ist das grösste Gewichtzu legen, wie die Versuche klar erkennen lassen. Im Einzelnen gestaltete sich das Verfahren so, dass, nachdem das Brom im Wasser durch den Zusatz der aufgelösten Tabletten unwirksem gemacht war, dem inficirten Wasser etwas gesättigte Sodalösung zugesetzt wurde', um für das Anreicherungsverfahren eine gute alkalische Reaction herzustellen. Dann wurde die ganze Wassermenge in kleine, 100 bis $200^{\mathrm{cm}}$ haltende Kölbchen vertheilt, und einem jeden soviel einer concentrirten Pepton-Kochsalzlösung zugesetzt, dass eine 1 procentige Pepton-Kochsalzlösung entstand. Die Kölbchen wurden 24 Stunden bei $37^{\circ}$ gehalten und dann von der Oberfläche eines jeden 3 Oesen in Röhrchen mit 1 Procent Pepton-Kochsalzlösung übertragen, welche wiederum 24 Stunden bei $37^{\circ}$ gehalten wurden. Nachdem die zweite Uebertragung stattgefunden, wurde mit den einzelnen Kölbchen die Cholerarothreaction angestellt, und wo eine solche nicht eintrat, wurde dieselbe mit dem entsprechenden Röhrchen am nächsten Tage noch einmal versucht, Diese Vorsicht 
Tabelle II.

\begin{tabular}{|c|c|c|c|c|c|c|c|}
\hline $\begin{array}{l}\dot{\vec{z}} \\
\dot{\vec{z}} \\
\dot{y}\end{array}$ & $\begin{array}{c}\text { Art } \\
\text { desWassers }\end{array}$ & $\begin{array}{l}\text { Ver- } \\
\text { suchs- } \\
\text { menge } \\
\text { Liter }\end{array}$ & $\begin{array}{c}\text { Zugesetzte } \\
\text { Menge einer } \\
\text { Agarcultur }\end{array}$ & $\left|\begin{array}{c}\text { Menge der } \\
\text { zugesetzten } \\
10 \text { procent. } \\
\text { Hüner- } \\
\text { m ann'- } \\
\text { schen Lösg. } \\
\text { in ccm }\end{array}\right|$ & $\begin{array}{c}\text { Ein- } \\
\text { wirkungs- } \\
\text { dauer } \\
\text { Minuten }\end{array}$ & $\begin{array}{c}\text { Zahl } \\
\text { der an- } \\
\text { gesetzten } \\
\text { Kölbchen }\end{array}$ & $\begin{array}{l}\text { Zahl der } \\
\text { die Roth- } \\
\text { reaction } \\
\text { gebenden } \\
\text { Kölbchen }\end{array}$ \\
\hline 1 & destillirtes & I & $1 / 2$ & 0.4 & 10 & 6 & 2 \\
\hline $1 \mathrm{a}$ & , & 1 & $1 / 2$ & 0.4 & 10 & 8 & 7 \\
\hline 2 & Leitung & 1 & $1 / 2$ & 0.4 & 10 & 9 & 9 \\
\hline $2 a$ & " & 1 & $1 / 2$ & 0.4 & 10 & 9 & 8 \\
\hline 3 & Brunnen & 1 & $1 / 2$ & 0.4 & 10 & 7 & 0 \\
\hline $3 a$ & , & 1 & $1 / 2$ & 0.4 & 10 & 10 & 10 \\
\hline 4 & Canal & 1 & $1 / 2$ & $0 \cdot 4$ & 10 & 6 & 0 \\
\hline $4 a$ & $"$ & 1 & $1 / 2$ & $0 \cdot 4$ & 10 & 8 & 8 \\
\hline 5 & destillirtes & 1 & $1 / 4$ & $0 \cdot 4$ & 10 & 8 & 8 \\
\hline 6 & Leitung & 1 & $1 / 4$ & 0.4 & 10 & 7 & 7 \\
\hline 7 & Brunnen & 1 & $1 / 4$ & 0.4 & 10 & 7 & 1 \\
\hline 8 & Canal & 1 & $1 / 4$ & 0.4 & 10 & 7 & 1 \\
\hline 9 & destillirtes & 1 & $\left|\begin{array}{c}3 \text { Oesen einer } \\
\text { Aufschwem- } \\
\text { mung in } 10^{\mathrm{ccm}}\end{array}\right|$ & 0.4 & 10 & 8 & 0 \\
\hline $9 a$ & ." & 1 & $"$ & 0.4 & 10 & 10 & 0 \\
\hline 10 & Leitung & 1 & ", & 0.4 & 10 & 7 & 0 \\
\hline $10 \mathrm{a}$ & " & 1 & ," & 0.4 & 10 & 7 & 2 \\
\hline 11 & Brunnen & 1 & , & 0.4 & 10 & 7 & 0 \\
\hline 11a & " & 1 & , & 0.4 & 10 & 8 & 2 \\
\hline 12 & Canal & 1 & , & $0 \cdot 4$ & 10 & 8 & 4 \\
\hline $12 a$ & , & 1 & $"$ & 0.4 & 10 & 7 & 6 \\
\hline 13 & destillirtes & 1 & $\begin{array}{c}1 \text { Oese einer } \\
\text { Aufschwem- } \\
\text { mung in } 10^{\mathrm{ccm}}\end{array}$ & 0.4 & 10 & 8 & 0 \\
\hline $13 a$ & ", & 1 & , & 0.4 & 10 & 10 & 0 \\
\hline 14 & Leitung & 1 & , & 0.4 & 10 & 8 & 0 \\
\hline $14 a$ & ", & 1 & ", & 0.4 & 10 & 8 & 1 \\
\hline 15 & Brunnen & 1 & , & 0.4 & 10 & 9 & 2 \\
\hline $15 a$ & $"$ & 1 & , & 0.4 & 10 & 9 & 2 \\
\hline 16 & Canal & 1 & , & 0.4 & 10 & 9 & 7 \\
\hline $16 a$ & , & 1 & , & 0.4 & 10 & 8 & 4 \\
\hline
\end{tabular}

erwies sich als durchaus erforderlich, dennes gelang mir verschiedene Male erst nach der zweiten Anreicherang, eine Rothreaction za erzielen. Anch stellte es sich bald heraus, dass es zweckmässiger war, das zum Anreichern und zu Rothreaction bestimmte Wasser in eine Anzahl kleiner Kolben zu vertheilen, als eben mit der ganzen Wassermenge in einem grösseren Gefäss diesen Versuch zu machen.

Selbstrerständlich wurde von jedem zum Versuch benutzten Wasser durch Controlkölbchen festgestellt, dass in demselben keine Rothbildner vorhanden waren." 
Die ResultatedieserVersuchsreihe sind rechtwenig günstige. Unter 28 Versuchen gelang es nur neun Mal, die Choleravibrionen in der angegebenen Zeit von 10 Minuten im Wasser völlig abzutödten; und der Werth dieses Erfolges reducirt sich bei näherer Betrachtung nicht unerheblich. Nur zwei Mal nämlich ergab, nachdem im ersten Versuch die Choleravibrionen vernichtet waren, die Wiederholung des Versuches das gleiche Resultat (Nr. 9 und $9 \mathrm{a}, 13$ und $13 a)$; in den übrigen Fällen $(3,3 a, 4,4 a, 10,10 a, 11,11 a, 14,14 a)$ ergaben die unter völlig gleichen Bedingungen angestellten Versuche ein Mal ein positives uni dann ein negatives Resultat; ausserdem handelte es sich bei den beiden mit ihren Wiederholungen übereinstimmenden Versuchen um solche, die mit destillirtem Wasser angestellt waren, also die günstigsten Chancen für das Gelingen boten, aber am wenigsten mit den Anforderungen für die praktische Anwendung des Verfahrens in Einklang zu bringen sind.

In den letzten acht Versuchen waren nur sehr geringe Mengen Choleravibrionen ( 1 Oese einer Culturaufschwemmung in $10^{\mathrm{cem}}$ Wasser, d. h. wenn man 1 Oese gleich $2^{\mathrm{mg}}$ und den Cubikcentimeter $2 \mathrm{u} 1_{\mathrm{grm}}$ rechnet $=1 / 5000$ Cultur) dem Wasser zugesetzt, trotzdem versagte das Verfahren unter acht Malen fünf Mal.

Es ist auch nicht ausser Acht zu lassen, dass alle Versuche mit Choleraculturen, die sehr lange auf künstlichen Nährböden fortgezüchtet sind, angestellt wurden, welche vielleicht weniger widerstandsfähig sind, als solche, die bei praktischer Anwendung des Verfahrens in Frage kommen.

Im Uebrigen beweisen diese Versuche wiederum, worauf ich schon früher hingewiesen, dass in einem Theile des Wassers die Choleravibrionen (und natürlich auch andere zu Versuchen benutzte Bakterien) vernichtet sein können, in einem anderen aber nicht, und dass es daher zur Gewinnung einwandsfreier Resultate dringend nöthig ist, die gesammte inficirte und zum Versuch benutzte Wassermenge auf entwickelungsfähige Vibrionen bezw. Keime zu untersuchen.

Bei einem Vergleich der Resultate der ersten beiden Versuchsreiben muss es auffallen, dass das Verfahren den an und für sich verhältnissmässig leicht zu vernichtenden Choleravibrionen sich nicht so bewährte wie bei den gewöhnlichen Wasserbalterien. Dies kann ein Mal darin seinen Grund haben, wie Schumburg schon bei seinen Versuchen vermuthete $^{1}$, dass die Bakterien in den Agarculturaufschwemmungen nicht S. $106-107$.

1 Veröffentlichungen aus dem Gebiete des Militär-Sanitätswesens. Heft 15. 
so fein vertheilt und der Einwirkung des Desinfectionsmittels nicht so sehr ausgesetzt seien wie z. B. die Wasserbakterien unter natürliehen Verbältnissen, andererseits kann aber der Grund darin liegen, dass die zum Nachweis der lebend, bezw. entwickelungsfähig gebliebenen Bakterien angewandten Methoden, im ersten Falle das gewöhnliche Plattenverfahren (allerdings mit je $10 \mathrm{~cm}$ Wasser), im anderen die Anreicherung der ganzen zum Versuche benutzten Wassermenge nicht gleichwerthige Resultate ergaben.

Um diese Frage zur Entscheidung zu bringen, wurde nach beiden Richtungen hin ein Versuch angestellt.

Zunächst wurden Versuche mit durch Filtrirpapier filtrierten Aufschwemmungen von Choleraculturen gemacht. Ich bemerke hier aber nochmals ausdrücklich, dass dies nur zu eben erwähntem Zwecke geschah, dass aber aus diesen Versuchen, soweit sie günstig ausfielen, aus früher eingehend erörterten Gründen ${ }^{1}$ gar nichts für die Brauchbarkeit des Hünermann'schen Verfahrens für die Praxis geschlossen werden darf. Die Versuche wurden im Uebrigen analug den in Tabelle II enthaltenen ausgeführt, und sind in der nächsten Tabelle zusammengestellt.

Tabelle III.

\begin{tabular}{|c|c|c|c|c|c|c|c|}
\hline 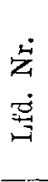 & $\begin{array}{l}\text { Art des } \\
\text { Wassers }\end{array}$ & $\begin{array}{l}\text { Ver- } \\
\text { suchs- } \\
\text { menge } \\
\text { Liter }\end{array}$ & $\begin{array}{l}\text { Zu- } \\
\text { gesetzte } \\
\text { Caltur- } \\
\text { menge } \\
\text { (filtrirt) }\end{array}$ & $\begin{array}{c}\text { Menge der } \\
\text { zugesetzten } \\
\text { Hüner- } \\
\text { mann'schen } \\
\text { Lösung in com }\end{array}$ & $\begin{array}{l}\text { Ein- } \\
\text { wirknugs- } \\
\text { dauer } \\
\text { Minuten }\end{array}$ & $\begin{array}{l}\text { Zahl der } \\
\text { angesetzten } \\
\text { Kolbchen }\end{array}$ & $\begin{array}{l}\text { Zahl der } \\
\text { die Roth- } \\
\text { reaction } \\
\text { gebenden } \\
\text { Kölbchen }\end{array}$ \\
\hline 1 & destillirtes & 1 & $1 / 2$ Cultur & 0.4 & 10 & 9 & 0 \\
\hline $1 \mathrm{a}$ & , & 1 & & $0 \cdot 4$ & 10 & 9 & 1 \\
\hline 2 & Leitung & 1 & & 0.4 & 10 & 7 & 0 \\
\hline $2 a$ & , & 1 & & $0 \cdot 4$ & 10 & 8 & 1 \\
\hline 3 & Brannen & 1 & $1 / 2$ & 0.4 & 10 & 10 & 0 \\
\hline $3 a$ & ", & 1. & $1 / 2$ & $0 \cdot 4$ & 10 & 9 & 6 \\
\hline 4 & Canal & 1 & $1 / 2$ & $0 \cdot 4$ & 10 & 7 & 6 \\
\hline $4 a$ & ," & 1 & $1 / 2$ & $0 \cdot 4$ & 10 & 10 & 4 \\
\hline
\end{tabular}

Also auch die Choleravibrionen in filtrirten Aufsehwemmungen wurden unter acht Mal nur drei Mal vernichtet (Nr. 1, $2,3)$ und bei der Wiederholung der drei Versuche nicht völlig (1a bis $3 a$ ).

${ }^{1}$ Diese Zeitschrift. Bd. XXXVII. S. 318. 
Hiernach ist es mir nicht wahrscheinlich, dass die Vertheilungsart der Keime im Wasser die merklichen Untersehiede zwischen den in der Tabelle I und II enthaltenen Resultaten verschuldet habe. Es handelte sich nun weiter um einen Vergleich der Leistungsfähigkeit des gewöhnlichen Plattenverfahrens mit grösseren Wassermengen, gegenüber dem Anreicherungsverfahren. Zu diesem Zweck wurden die Aufschwemmungen der Choleraculturen in sterilem Wasser gemacht und den sorgfältig sterilisirten und auf Keimfreiheit geprüften verschiedenen Wasserarten zugesetzt. Es geschah dies deshalb, um auf den Platten, soweit Colonieen wuchsen und zu zählen waren, nur Cholera zu haben. Nachdem das Hünermann'sche Verfahren durchgeführt war, wurden zunächst von jedem Liter Wasser mittels steriler Pipetten je vier $\mathrm{Mal}$ $10^{\mathrm{cm}}$ entnommen, in grossen Schalen zu Agarplatten verarbeitet, und 24 Stunden bei $37^{\circ}$ belassen. Der Rest des Wassers $\left(960^{\mathrm{ccm}}\right.$ ) wurde mittels Anreicherungsverfahren und Cholerarothreaction wie bei den anderen Versuchen untersucht.

Am nächsten Tage wurden die auf den Platten zur Entwickelung. gekommenen Keime der Sicherheit halber noch in Röhrchen mit Peptonlösung abgeimpft zur Anstellung der Rothreaction, obgleich, abgesehen von Luftkeimen, kaum etwas Anderes als Cholera auf den Platten zur Entwickelung kommen konnte. Das Resultat dieser in der nächsten Tabelle enthaltenen Versuchsreihe war ein recht überraschendes und lehrreiches:

Tabelle IV.

\begin{tabular}{|c|c|c|c|c|c|c|c|c|c|}
\hline 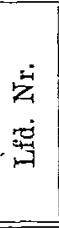 & $\begin{array}{l}\text { Art des } \\
\text { Wassers }\end{array}$ & 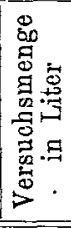 & 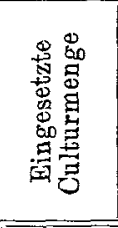 & 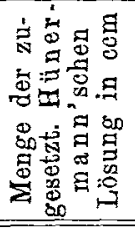 & 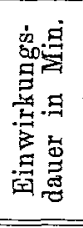 & 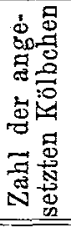 & 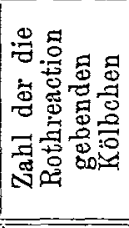 & \multicolumn{2}{|c|}{$\begin{array}{l}\text { Zahl der-Colo- } \\
\text { nieen auf je vier } \\
\text { Platten in } 10 \mathrm{ccm} \\
\text { darunter }\end{array}$} \\
\hline 1 & destillirtes & 1 & 1 & 0.4 & 10 & 9 & 9 & 0 & 2 \\
\hline 2 & Leitung & 1 & $1 / 2$ & 0.4 & 10 & 8 & 2 & 0 & 0 \\
\hline 3 & Brannen & 1 & 3 Oesen & $0 \cdot 4$ & 10 & 8 & 1 & 0 & 4 \\
\hline 4 & Canal & 1 & 3 & $0 \cdot 4$ & 10 & 10 & 7 & 0 & 0 \\
\hline
\end{tabular}

Bei der näheren Prüfung der auf den Agarplatten gewachsenen Colonieen ergab sich, was schon mikroskopisch wahrscheinlich erschien, dass es sich nur um darauf gefallene Luftkeime und nicht auch nur bei einer einzigen Colonie um Cholera handelte! 
Es stellte sich also heraus, dass in den vier Versuchen das Plattenverfabren bei $37^{\circ}$ mit je $40^{\mathrm{em}}$ Wasser keine Choleravibrionen mehr zur Entwickelung kommen liess - selbst dort nicht, wo sämmtliche Kolben Rothreaction gaben (Nr. 1) - , während mittelst der Anreicherungsmethode in jedem Falle noch entwickelungsfähige Vibrionen in mehr oder minder grosser Menge nachgewiesen werden konnten.

Hiermit ist die Ueberlegenheit des Anreicherungsverfahrens über das bisher so viel geübte Plattenverfahren und die eventuelle Unzulänglichkeit des letzteren für derartige Untersuchungen, wie die vorliegenden, besiegelt.

Diese Resultate lassen mir nachträglich noch die Differenzen zwischen meinen Resultaten und denen Schumburg's und A. Pfuhl's bei den Untersuchungen über die Einwirkung des Bromverfahrens auf Choleravibrionen im Wasser, welche ich damals ${ }^{1}$ mit den verschieden grossen zum Nachweis derselben benutzten Mengen des bromirten Wassers zu erklären suchte, in anderem Lichte erscheinen. Vielleicht sind es damals nicht einzig und allein die verschiedenen Versuchsmengen ( $1{ }^{\mathrm{cm}}$ und die ganze zum Versuch benutzte Wassermenge) gewesen, sondern auch der Unterschied zwischen dem Plattenverfahren and der Anreicherungsmethode, welche solche grosse Differenzen in den Resultaten zeitigten.

Das Ergebniss der letzten Versuche veranlasste mich, nun doch nochmals auf die erste Versuchsreihe zurückzugreifen und den dort schon angedeuteten Versuch anzustellen, in Wasser, welches nach dem Plattenverfahren keimfrei erschien, mittels des Anreicherungsverfahrens noch nach entwickelungsfähigen Keimen zu suchen.

Es wurde genau wie in der ersten Versuchsreihe gearbeitet, und nur nach Entnahme der $10^{\mathrm{cem}}$ für die Platten mittels steriler Pipette der ganzen übrigen Wassermenge eine sterile, concentrirte Kochsalz-Peptonlösung zugesetzt und dieselbe bei $22^{\circ}$ gehalten. Täglich wurden dann Gelatineplatten mit je 1.0 nnd $0.1 \mathrm{com}$ angelegt und bei $22^{\circ}$ auf bewahrt.

Wie die Tabelle $V$ zeigt, waren beim Versuch 3 und 4 schon mit dem Plattenverfahren entwickelungsfähige Keime nachgewiesen, und konnte daher nur noch für Versuch 1 und 2 das Anreicherungsverfahren zum Vergleich herangezogen werden.

Das Resultat stand in völliger Uebereinstimmung mit dem der Versuche mit Cholera.

${ }^{1}$ Diese Zeitschrift. Bd. XXXVII. S. 317. 
SCHÜDER:

Tabelle V.

\begin{tabular}{|c|c|c|c|c|c|c|}
\hline 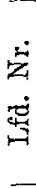 & $\begin{array}{l}\text { Art des } \\
\text { Wassers }\end{array}$ & $\begin{array}{c}\text { Versuchs- } \\
\text { menge } \\
\text { Liter }\end{array}$ & $\begin{array}{c}\text { Menge der } \\
\text { zugesetzten } \\
\text { Hüner- } \\
\text { mann'schen } \\
\text { Lösung in ecm }\end{array}$ & $\begin{array}{c}\text { Einwirkungs- } \\
\text { dauer } \\
\text { Minuten }\end{array}$ & $\begin{array}{l}\text { Zabl der zur } \\
\text { Entwikelung } \\
\text { gekommenen } \\
\text { Colonieen auf } \\
\text { Gelatineplatte } \\
\text { mit } 10 \text { ccm }\end{array}$ & $\begin{array}{l}\text { Platten nach } \\
\text { dem An- } \\
\text { reicherungs- } \\
\text { verfahren }\end{array}$ \\
\hline 1 & destillirtes & 1 & $0 \cdot 4$ & 10 & 0 & $\begin{array}{l}\text { übersät mit } \\
\text { Colonieen }\end{array}$ \\
\hline 2 & Leitung & 1 & $0 \cdot 4$ & 10 & 0 & " \\
\hline 3 & Brunnen & 1 & $0 \cdot 4$ & 10 & 5 & - \\
\hline 4 & Canal & 1 & 0.4 & 10 & 3 & - \\
\hline
\end{tabular}

Schon die Platten, welche 24 Stunden nach der Anreicherung angelegt waren, waren nach weiteren 24 Stunden mit Colonieen übersät.

Das nach dem Plattenverfahren keimfrei erscheinende Wasser beherbergte also doch noch entwickelungsfähige Keime.

Dieses Resultat lässt das an und für sich so günstige der Tabelle I denn doch noch in anderem Lichte erscheinen, indem Zweifel, ob bei den Versuchen völlige Keimfreiheit bezw. eine so hochgradige Reduction der Keimzahl, wie sie das Plattenverfahren ergeben, in Wirklichkeit erreicht ist, wohl mehr als berechtigt sind.

\section{3.}

Für die dritte Versuchsreihe dienten Typhusbacillen als Versuchsobject. Die Versuchsanordnung war die, dass die za inficirenden Wasserarten vorher sorgfältigst sterilisirt wurden, um später bei der Identificirung der gewachsenen Colonieen keine Schwierigkeiten in Folge anderer, aus dem Wasser stammender und noch zur Entwickelung gekommener Keime zu haben. Das Agglutinationsverfahren mit einem Serum 1:100 verdünnt, diente zur Erkennung der gewachsenen Typhusbacillen. Zunächst wurde zum Nachweis der lebend gebliebenen Typhuskeime nur das Agarplattenverfahren mit je 10 cem Wasser angewandt, als aber schon in den Versuchen Nr. 1, $3 a, 4,7$ u. 8 nur wenige und bei Nr. 5 u. 6 gar keine Typhuscolonieen auf den gewöhnlichen Agarplatten zur Entwickelung kamen, wurde bei den Versuchen Nr. 9 bis $16 \mathrm{a}$ das Anreicherungsverfahren mittels steriler Pepton-Kochsalzlösung bei $37^{\circ} 24$ Stunden angewandt und dann erst das Plattenverfahren. $\mathrm{Zu}$ letzterem wurde ausserdem nicht der gewöhnliche Agar benutzt, sondern ein besonderer Nährboden, welcher die Typhuscolonieen ganz charakteristisch wachsen lässt ${ }^{1}$, so dass dieselben schon

${ }^{1}$ Ueber denselben wird in nächster Zeit von Stabsarzt Dr. v. Drigalski und Dr. Conradi, welchen die Herstellung gelungen, berichtet werden. - Anmerkung 
makroskopisch deutlich von anderen zn unterscheiden sind. Es wurden die Untersuchungen dadurch sehr erleichtert, aber trotzdem nicht verabsäumt, in jedem Falle auch noch die Agglntinationsprobe zu machen.

Die Benutzung dieses Nährbodens bot noch den weiteren Vortheil, dass in jedem Fall zu sehen war, ob es gelungen war, die Versuche von Anfang bis zu Ende steril, d. h. unter Ausschluss aller anderen, als der Typhrusbakterien durchzuführen. Wie ich gleich bemerken will, ist dies unter den 12 Versuchen $11 \mathrm{Mal}$ vollkommen gelungen, und bei der einen Ausnahme waren neben den bei Weitem überwiegenden Typhuscolonieen einige wenige andere Colonieen zur Entwickelung gekommen, welche wegen ihrer minimalen Anzahl nicht stören konnten.

Vor dem Anreicherungsverfahren und der Anwendung des besonderen Nährbodens wurden zu Vergleichszwecken stets auch noch gewöhnliche Agarplatten mit $10^{\mathrm{cem}}$ Wasser angelegt.

Eine Uebersicht über die gewonnenen Resultate giebt die nächste Tabelle VI. Der Vollständigkeit der Versuche halber sind auch Versuche mit filtrirter Culturaufschwemmung hinzugefügt (Nr. 17 bis 20).

Lässt man bei Betrachtung des Inhalts der Tabelle zunächst die letate Spalte ausser Acht, so würde eine erhebliche Einwirkung des Verfahrens auf Typhusbacillen nicht zu verkennen sein. Unter 28 Versuchen waren $9 \mathrm{Mal}$ Typhusbacillen in $10^{\mathrm{ccm}}$ Wasser mittels des Plattenverfahrens überhaupt nicht mehr und $11 \mathrm{Nal}$ nur in einzelnen Exemplaren nachzuweisen, während $7 \mathrm{Mal}$, darunter $2 \mathrm{Mal}$ bei filtrirter Culturaufschwemmung (Nr. 18 u. 20), noch zahlreiche Typhusbacillen lebend geblieben waren.

Sobald man aber die in der letzten Spalte der Tabelle enthaltenen Lirgebnisse mit in Rechnung zieht, ändert sich das Bild vollkommen. Nach Anwendung des Anreicherungsverfahrens ist unter 16 Versuchen nicht ein einziges Nal die völlige Vernichtung der Typhuskeime gelungen - während es nach dem gewölnlichen Plattenverfahren unter diesen 16 Versuchen $7 \mathrm{Mal}$ der Fall gewesen sein sollte - auch dann nicht, wenn zur Einsaat nur eine geringe Menge Typhusbacillen (3 Oesen einer Aufschwemmung im Condenswasser der Cultur) benutzt worden war. -

Die Versuche bestätigen, abgesehen von der ungenügenden Wirkung des Verfahrens Typhusbacillen gegenüber, ebenso wie die vorhergehenden die Unzulänglichkeit des bisher geübten Plattenverfahrens für derartige Untersuchungen.

bei der Correctur: Die Veröffentlichung ist inzwischen erfolgt in dieser Zeitschrift. Bd. XXXIX. S. 291-297. 
Tabelle VI.

\begin{tabular}{|c|c|c|c|c|c|c|c|}
\hline 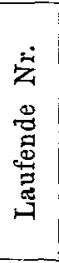 & $\begin{array}{l}\text { Art des } \\
\text { Wassers }\end{array}$ & 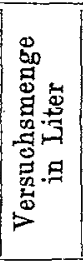 & $\begin{array}{c}\text { Zugesetzte } \\
\text { Culturmenge }\end{array}$ & $\begin{array}{c}\text { Menge der } \\
\text { zugesetzten } \\
\text { Hüner- } \\
\text { mann'schen } \\
\text { Lösung } \\
\text { in ccm }\end{array}$ & 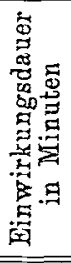 & $\begin{array}{c}\text { Typhus- } \\
\text { Colonieenzanl } \\
\text { auf Agar- } \\
\text { platten } \\
\text { mit je } 10^{\mathrm{ccm}} \\
\text { Wasser }\end{array}$ & $\begin{array}{l}\text { Typhuscolon. } \\
\text { anf Platten, } \\
\text { 3. u. 4. Ver- } \\
\text { dünnung von } \\
\text { je } 0 \cdot 1 \text { Wasser } \\
\text { nach dem An- } \\
\text { reichertngs- } \\
\text { verfahren }\end{array}$ \\
\hline 1 & destillirtes & 1 & $1 / 4$ Cultur & 0.4 & 10 & 3 & - \\
\hline $1 \mathbf{a}$ & , & 1 & $1 / 4 \quad$, & 0.4 & 10 & sehr zahlreich & - \\
\hline 2 & Leitung & 1 & $1 / 1 \quad$, & $0 \cdot 4$ & 10 & & $\rightarrow$ \\
\hline $2 \mathrm{a}$ & , & 1 & $1 / 4$ & 0.4 & 10 & $\begin{array}{l}\text { Platte ver- } \\
\text { dorben }\end{array}$ & - \\
\hline 3 & Brunnen & 1 & $1 / 4$ & 0.4 & 10 & sehr zahlreich & - \\
\hline $3 a$ & , & 1 & $1 / 4 \quad$, & $0 \cdot 4$ & 10 & 2 & - \\
\hline 4 & Canal & 1 & $1 / 4 \quad$, & 0.4 & 10 & 7 & - \\
\hline $4 a$ & " & 1 & $1 / 4$ & $0 \cdot 4$ & 10 & sehr zahlreich & - \\
\hline 5 & destillirtes & 1 & 1 Oese Cultur & $0 \cdot 4$ & 10 & 0 & - \\
\hline 6 & Leitung & 1 & $1 \%$ & $0 \cdot 4$ & 10 & 0 & - \\
\hline 7 & Brannen & 1 & $1 \%$ & $0 \cdot 4$ & 10 & 2 & - \\
\hline 8 & Canal & 1 & $1 \Rightarrow$, & $0 \cdot 4$ & 10 & 1 & - \\
\hline 9 & destillirtes & 1 & $1 / 4$ Coltur & $0 \cdot 4$ & 10 & 2 & $\begin{array}{l}\text { übersät mit } \\
\text { Colonieen }\end{array}$ \\
\hline 10 & Leitung & 1 & $1 / 4 \quad$, & $0 \cdot 4$ & 10 & 3 & $"$ \\
\hline 11 & Brunnen & 1 & $1 / 4 \quad$, & $0 \cdot 4$ & 10 & 5 & " \\
\hline 12 & Canal & 1 & $1 / 4 \quad$, & 0.4 & 10 & 2 & " \\
\hline 13 & destillirtes & 1 & $\begin{array}{c}3 \text { Oesen Con- } \\
\text { denswasser- } \\
\text { Aufschwem- } \\
\text { mung }\end{array}$ & $0 \cdot 4$ & 10 & 0 & " \\
\hline $13 a$ & $"$ & 1 & , & 0.4 & 10 & 0 & , \\
\hline 14 & Leitung & 1 & ” & 0.4 & 10 & 0 & " \\
\hline $14 \mathrm{a}$ & , & 1 & " & $0 \cdot 4$ & 10 & 0 & $"$ \\
\hline 15 & Brunnen & 1 & , & 0.4 & 10 & 7 & " \\
\hline $15 a$ & ” & 1 & $"$ & $0 \cdot 4$ & 10 & 0 & ” \\
\hline 16 & Canal & 1 & " & 0.4 & 10 & sehr zablreieh & $"$ \\
\hline $16 \mathbf{a}$ & , & 1 & , & $0 \cdot 4$ & .10 & 0 & $"$ \\
\hline 17 & destillirtes & 1 & $\begin{array}{l}1 / 4 \text { Cultur } \\
\text { filtrirt }\end{array}$ & 0.4 & 10 & 0 & , \\
\hline 18 & Leitang & 1 & $1 / 4 \quad$, & $0 \cdot 4$ & 10 & zablreich & $"$ \\
\hline 19 & Brunnen & 1 & $1 / 4$ & 0.4 & 10 & 3 & " \\
\hline 20 & Canal & 1 & $1 / 4$ & $0 \cdot 4$ & 10 & sehr zahlreich & ", \\
\hline
\end{tabular}


4.

In der vierten und letzten Versuchsreihe dienten Ruhrbacillen ${ }^{I}$ als Versuchsobject. Es wurde in gleicher Weise mit sterilen Materialien gearbeitet wie bei den Versuchen mit Typhus, und neben dem Plattenverfahren das Anreicherungsverfahren mit nachfolgender Benutzung von Platten aus einem besonderen Nährboden ${ }^{1}$ für Ruhrbacillen, sowie der Agglutinationsprobe angewendet.

Das Ergebniss war folgendes:

Tabelle VIr.

\begin{tabular}{|c|c|c|c|c|c|c|c|}
\hline $\begin{array}{l}\dot{\mathrm{Z}} \\
\dot{0} \\
\dot{9}\end{array}$ & $\begin{array}{l}\text { Art des } \\
\text { Wassers }\end{array}$ & 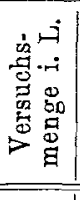 & $\begin{array}{l}\text { Zu- } \\
\text { gesetzte } \\
\text { Cultur- } \\
\text { menge }\end{array}$ & $\begin{array}{c}\text { Menge der } \\
\text { zugesetzten } \\
\text { Hün er- } \\
\text { mann'schen } \\
\text { Lösung } \\
\text { in ccm } \\
\end{array}$ & 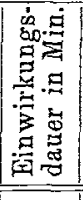 & $\begin{array}{c}\text { Rubr- } \\
\text { colonieenzahl } \\
\text { auf Agar- } \\
\text { platten mit } \\
10 \mathrm{ccm}\end{array}$ & $\begin{array}{l}\text { Ruhrcolonieen- } \\
\text { zahl auf Platten, } \\
\text { 3. Verdünnung } \\
\text { mit } 0 \cdot 1 \text { ccm nach } \\
\text { dem Anreiche- } \\
\text { rungsverfahren }\end{array}$ \\
\hline 1 & destillirtes & 1 & $1 / 4$ Cultur & 0.4 & 10 & 0 & sehr zahlreich \\
\hline $1 \mathrm{a}$ & " & 1 & $1 / 4$ & 0.4 & 10 & 0 & übersät \\
\hline 2 & Leitung & 1 & $1 / 4$ & $0 \cdot 4$ & 10 & 0 & ", \\
\hline $2 a$ & ," & 1 & $1 / 4$ & $0 \cdot 4$ & 10 & 0 & " \\
\hline 3 & Brannen & 1 & $1 / 4$ & $0 \cdot 4$ & 10 & 0 & , \\
\hline $3 a$ & , & 1 & $1 / 4$ & $0 \cdot 4$ & 10 & 0 & $"$ \\
\hline 4 & Canal & 1 & $1 / 4$ & $0 \cdot 4$ & 10 & 0 & , \\
\hline $4 a$ & " & 1 & $1 / 4$ & $0 \cdot 4$ & 10 & 0 & keine \\
\hline
\end{tabular}

Das Resultat ist also analog den vorhergehenden Versuchen. Die Ruhrbacillen werden nicht mit Sicherheit abgetödtet. Trotzdem mittels des Plattenverfahrens in $10 \mathrm{~cm}$ keine mehr nachzuweisen waren, ergab das Anreicherungsverfahren unter 8 Malen 7 Mal ein positives Resultat. Auf einzelnen Platten waren einige Colonieen ron Luftkeimen gewachsen.

Bevor ich das Gesammtresultat meiner Untersuchungen zusammenfasse, möchte ich noch eine Erklärung für diese abweichendeu Resultate des Plattenverfahrens zu geben versuchen. Wie einige Versuche zeigten, in denen auf Agarplatten, von einer Aufschwemmung einer Oese Cultur in 1 Liter sterilisirtem Wasser angelegt, nach 24 Stunden bei $37^{\circ}$ ein sehr reichliches Wachsthum der eingesäten Bakterien stattgefunden hatte, kann es sich bei der Anwendung des Plattenverfahrens ebenso wenig um eine Schädigung der Bakterien auf plasmolytischem Wege durch das Uebertragen aus dem zum Versuch dienenden Wasser in dem salzhaltigen Nähragar, wie um eine mangelhafte Beschaffenheit des benutzten Nähragars gehandelt haben.

1 Veröffentlichung hierüber von anderer Seite steht noch bevor. 
Auch die anerkannt rapide Vermehrung der Balterien in ibnen zusagenden Nährböden reicht wohl für eine genügende Erklärung nicht aus. Denn wenn sich z. B. bei den Versuchen mit Typhus wirklich in $10 \mathrm{cem}$ nur 2 bis 3 bis 4 noch entwickelungsfähige Keime gefunden hätten, während sich nach der Anreicherung auf den Verdünnungen der mit $0.1 \mathrm{~cm}$ angelegten Platten noch bis $\mathbf{9 0 0}$ Colomieen fanden, so würde das heissen, dass eine Vermehrung in 24 Stunden stattgehabt haben musste; die jede Verstellung eigentlich übersteigt.

Die an meisten Wahrscheinlichkeit für sich habende Erklärung ist mir die, dass das dem Wasser zugesetzte Desinfectionsmittel (vielleicht auch im Verein mit dem später zugesetzten Bindemittel) durch Kindringen und Haftenbleiben in den Bakterienhüllen einen Theil derselben zunächst nur in ihrer Entwickelungsfähigkeit geschädigt hat. Während nun bei der Anreicherung im flüssigen, zum weitaus grössten Theil aus Wasser bestehenden Näbrboden auf endosmotischem Wege die Bakterien die sie uur schädigenden Substanzen bald wieder abgeben, bleibt dieser Vorgang auf festen Nährböden aus, oder gebt nur so langsam vor sich, dass eine bleibende Wachsthumshemmung die Folge ist.

Eime solche Erklärung würde nicht nur mit sämmtlichen Ontersuchungsresultaten im Einklang stehen, sondern durch einzelne derselben noch eine besondere Stütze erfahren, nämlich durch alle diejenigen, in denen die Platten steril blieben und das Anreicherungsverfahren die entwickelungsfähig gebliebenen Keime nachwies.

Ganz besonders möchte ich in dieser Beziehung den Versuch Nr. 1 der Tabelle IV hervorheben. Hier waren nach dem Chlorverfahren soviel Choleraribrionen entwickelungsfähig geblieben, dass in jedem der 9 Kölbchen, in welche die zum Versuch benutzte Wassermenge gethan war, nach der Anreicherung eine ausgesprochene Rothreaction auftrat, während das Plattenverfahren vor der Anreicherung, trotzdem $40 \mathrm{~cm}$ des Wassers, also der 25. Theil der ganzen Versuchsmenge (in der eine gleichmässige Vertheilung des eingesäten Volumens stattgefunden) und ungefähr die Hälfte der in einem der Kölbchen enthaltenen Wassermenge, hierzu benutzt waren, nicht einen einzigen noch entwickelungsfähigen Choleravibrio uachwies! -

Die Thatsache der Unzuverlässiglieit des Plattenverfahrens für den Nachweis der nach Desinfectionsversuchen noch entwickelungsfähig gebliebenen Keime überhaupt, wie auch ihrer 
Zahl nach, ist ganz besonders hervorzuheben, weil gerade neuere und neueste Arbeiten das Plattenverfahren bei der Prüfung von Desinfectionsmitteln wieder in den Vordergrund stellen.

So sind 1897 Krönig und Paul bei allen ihren so zahlreichen, mit Desinfectionsmitteln aller drt angestellten Versuchen ${ }^{1}$ von den flüssigen Nāhrböden abgegangen und zu einem ganz gleichmässig dargestellten Agar übergegangen, weil die flüssigen Nährböden nicht erlaubten, festzustellen, wie riele Bakterien nach der Desinfection noch keimfähig igeblieben wären. ${ }^{2}$ Dies erlaubt nun aber, wie meine Versuche feststellen, auch das Agarplattenverfahren nicht, denn ausser den auf den Platten zum Wachsthum gekommenen Keimen lönnen sich zweifellos unter den eingefübrten viele befunden haben, die auf anderen, günstigeren (flüssigen) Nährböden noch zur Entwickelung gekommen wären und daher nicht als „entwickelungsunfähig" ohne Weiteres bezeichnet werden können und in den Versuchen von Krönig und Paul Platten ohne Wachsthum erhielten, ist damit durchaus nicht bewiesen, dass die eingesäten Bakterien überhaupt nicht mehr entwickelungsfähig waren. Nebenbei sei noch bemerkt, dass genannte Autoren, wohl in Folge des Plattenverfahrens, viel zu kleine Aussaatmengen zum Nachweis eben noeh entwickelungsfähiger Keime benutzt haben. Auch in einer erst im April v. Js. erschienenen Arbeit: „Entwurf zur einheitlichen Werthbestimmung chemischer Desinfectionsmittel mit besonderer Berücksichtigung der neuen Theorien der Lösungen" sagt Paul ${ }^{3}$, nachdem er seine und Krönig's Forderung: „Die Zahl der noch entwickelungsfähig gebliebenen Balsterien muss nach Ablauf derselben Zeit festgestellt werden, aus diesem Grunde können nur feste Nährböden benutzt werden", citirt hat", dass wir bei Desinfectionsversuchen für quantitative Versuche an der Verwendung fester Nährböden festhalten müssen. ${ }^{5}$ Fr schlägt daher für die Ausführung der einheitlichen Werthbestimmung den Agarnährboden von gleichmässiger Herstellung vor.

Ich bin auf Grund meiner Versuche za der Ueberzengung. gekommen, dass wir bisher keine Untersuchungsmethode besitzen, um die keimschälligende Wirkung eines Desinfectionsmittels quantitatir mit Sicherheit zu bestimmen, - und damit wird auch die vergleichsweise Bestimmung unsicher - denn das allein für solchen Zweck anwendbare Plattenverfahren ist

${ }^{1}$ Ueber die Grundlagen der Lehre von Giftwirkung und Desinfection. Diese Zeitschrift. Bd. XXV. S. 1-112.

${ }^{2}$ Ebenda. S. 16.

${ }^{3}$ Zeitschrift für angevandte Chemie. 1901. S. 333 u. 357.

4 Evenda. S. 337.

5 Ebenda. S. $35 \overline{7}$. 
nicht zuverlässig genug. Dasselbe erlaubt böchstens von ,auf Agar bezw. Gelatine nicht mehr entwickelungsfähigen Keimen" zu sprechen, was für die praktische Anwendbarkeit eines Desinfectionsmittels unter Umständen recht wenig bedeuten kan $n$, wie meine Versuche zeigen, und ausserdem gestattet das Verfahren immer nur verhältnissmässig kleine Materialmengen ohne grössere Schwierigkeiten zu durchsuchen.

Wir können nur mittels Anwendung flüssiger Nährböden, Anreicherung, Benutzung grösserer Mengen Untersuchungsmaterials und dann erst folgendem Plattenverfahren feststellen, $o b$ ein Desinfectionsmittel alle eingesäten Keime entwickelungsunfähig gemacht hat oder nicht, und das bleibt für die Beurtheilung des praktischen Werthes solcher Mittel stets die Hauptsache.

Mein Schlussurtheil über das geprüfte Hünermann'sche Verfahrén muss ich dahin zusammenfassen:

1. Das Verfahren scheint den Keimgehalt eines auch stärker verunreinigten und sehr bakterienreichen Wassers erheblich herabzusetzen, in einzelnen Fällen dasselbe vielleicht auch völlig keimfrei zu machen.

2. Das Verfahren vernichtet in einzelnen Fällen Cholerakeime mit Sicherheit, doch bilden diese Fälle nur die Ausnahme. Häufig findet aur eine sehr erhebliche Verringerung der Zahl statt.

3. Typhusbacillen werden nicht sicher vernichtet, wenn auch eine gewisse Schädigung derselben in vielen Fällen unverkennbar ist.

4. Auch filtrirten Culturaufschwemmungen ron Choleraund Typhusbakterien gegenüber ist das Verfahren durchaus nicht zuverlässig.

5. Ruhrbacillen werden nicht sicher vernichtet, trotzdem dieselben nach den bisherigen Erfahrungen zu den leicht zu vernichtenden pathogenen Keimen zu gehören scheinen.

6. Das Hünermann'sche Verfahren scheint im Ganzen eine grössere keimschädigende Wirkung als das Schumburg'sche Verfahren mittels Brom auszuüben ${ }^{2}$, namentlich gegenüber den Typhuserregern, auf welche es bei uns in erster Linie ankommen würde. ${ }^{1}$

${ }^{1}$ Auch Bollner (Wiener med. Wochenschrift, 1901, Nr. 31-33) spricht dem Chlor eine intensivere Wirkung als dem Brom zu, indem er sagt: ,in ihrer sterili- 
Wenn nun auch nach heutigen Anschauungen ein Wasser, welches nachweislich noch entwickelungsfähige Krankheitserreger enthält, vom Genuss und überhaupt vom Gebrauch anszuschliessen ist, so dürfte es doch vielleicht durchaus nicht gleichgültig sein, in welchen Mengen, bezw. in wieweit in ihrer Entwickelungsfähigkeit geschädigt pathogene Keime von Menschen aufgenommen werden. Das Hünermann'sche Verfahren dürfte daher immerhin einen wesentlichen Fortschritt bedeuten und bei einer etwa möglichen Vervollkommnung das erstrebenswerthe Ziel einer völligen Vernichtung von pathogenen Keimen im Wasser vielleicht ganz erreichen. $\mathrm{Ob}$ eine längere Finwirkung der Chlorlösung, oder. grossen Mengen derselben, oder Beides günstigere Ergebnisse zeitigen würden, müssten Versuche lehren. Die praktische Verwendbarkeit des Verfahrens würde aber jedenfalls durch die Forderung einer 20 Minuten oder noch länger dauernden Einwirkung der Chlorlösung eine erbebliche Einschränkung erfahren, sind doch schon 10 Minuten für solche $Z$ wrecke praktisch eine recht lange Zeit!

Die grossen Unterschiede zwischen Hünermanu's und meinen Untersuchungsresultaten finden ihre Erklärung in der Verschiedenheit der angewandten Untersuchungsmethoden z. Th. wobl auch nebenher darin, dass Hünermann mit filtrirten Culturaufschwemmungen gearbeitet hat. Hünermann ist wohl bei seinen Untersuchungen ähnlich wie s. Zt. Sehumburg und A. Pfuhl beim Bromverfahren in erster Linie durch die Benutzung viel zu kleiner Mengen des Untersuchungsmaterials und auch durch die Unzuverlässigkeit des Plattenverfahrens. irregeführt worden.

Zum Schlusse meiner Arbeit möchte ich nun noch kurz die Anforderungen präcisiren, welche meiner Ansicht nach bei Untersuchungen, wie die vorliegende und ähnlichen an die Untersuchungsmethode gestellt werden müssen, um zu einwandsfreien Resultaten zu gelangen.

1. Das bisher geübte Plattenverfahren (Agar, Gelatine) mit festen Nährböden ist nur dann ausschlaggebend, wenn die Platten nicht steril bleiben, bezw. wenn sich auf denselben die zu den Versuchen benutzten Keime wiederfinden. Zweckmässig sind Platten mit mindestens $10^{\mathrm{cem}}$ des Untersuchungsmaterials, oder auch mehrere solche.

sirenden Wirkang erweisen sich also beide Verfahren (Loden, Schumburg) wenn auch vielleicht nicht als gleichwerthig, so doch genügend zuverlässig“" und "das ChIorkalkverfahren lässt uns als das in bakteriologischer Hinsicht überlegene erscheinen“. Allerdings hat Bollner bei seinen vergleichenden Untersuchungen mit beiden Verfahren nicht mit Cholera und Typhus gearbeitet. 
2. Bleiben solche Platten nicht steril, so kann die auf ihnen zur Entwickelung gekommene Colonieenzahl nicht ohne Weiteres zu einem Schluss auf die Menge der vernichteten Keime dienen, denn es können solche Platten noch eine grosse Anzahl nur geschädigter Keime enthalten, welche unter günstigeren Bedingungen noch entwickelungsfähig sind; das wirkliche Reductionsverhältniss ist also nicht zu ermitteln.

3. Bleiben die Platten mit festen Nährböden steril, so ist in jedem Falle a) eine der Eigenart des zum Versuch benutzten Bacteriums entsprechende Anreicherungsmethode vor dem Plattenverfahren einzuschalten, und b) hierzu, wenn irgend möglich, die ganze zum Versuch benutzte bezw. inficirte Menge - bei Untersuchungen im grösseren Styl mindestens aber ein Quantum von einem oder einigen Litern - zu verwenden.

4. Für Untersuchungen mit Choleravibrionen ist ein Anreicherungsverfahren sehr leicht durchzuführen, weil man anstatt des nachfolgenden Plattenverfahrens direct die Cholerarothreaction benutzen kann, und daher nicht steril zu arbeiten braucht. Ein Controlversuch hat nur nachzuweisen, dass das zu den Versuchen benutzte Wasser keine Rothbildner von vorn. herein enthalten hat.

5. Auch für Typhus- und Ruhrbacillen ist wie bei meinen Versuchen ein Anreicherungsverfahren ohne allzu grosse Mühe durchzuführen, sobald man unter Ausschluss anderer Keime durch Sterilisation des zum Versuch dienenden Wassers u. s. w. arbeitet. Eine Erleichterung bieten noch beim nachfolgenden Plattenverfahren die erwähnten besonderen Nährböden. Zweckmässig dürfte bei der Anreicherung auch hier eine Vertheilung der zum Versuch benutzten Wassermenge in eine grössere Anzahl kleiner Kölbchen sein, um eingenaueres Urtheil über den Effect der Desinfection zu erlangen.

6. Sollen andere Bakterienarten als Versuchsobjecte dienen, so ist sinngemäss zu verfahren.

7. Jeder Versuch ist zu wiederholen.

Zuletzt möchte ich noch die Vermuthung aussprechen, dass möglicher Weise einzelne bisher als gute Desinfectionsmittel angesehene Substanzen, bezw. deren bisher übliche Concentration und Einwirkungsdauer sich bei näherer Prüfung nach den soeben aufgestellten Grundsätzen weniger zuverlässig, als bisher 
geglaubt, erweisen könnten, was praktisch unter Umständen von weitragender Bedeutung sein würde. Es würden Versuche nach dieser Richtung sich wohl lohnen, so z. B. mit dem im Grossen bei der Abwässerreinigung gebrauehten Chlorkalk ${ }^{1}$, welcher bisher als zuverlässiges Desinfectionsmittel für Trinkwasser gegolten hat und ausserdem in neuerer Zeit für die Desinfection mit Typhusbacillen inficirter Badewässer als leicht erhältliches, billiges, ungefährliches und sicher wirkendes Desinfectionsmittel empfohlen ist. ${ }^{2}$

${ }^{1}$ Dunbar-Zirn, Beitrag zar Frage über die Desinfection städtischer Abwässer. Bygienische Rundschau. 1899. S. 406. - Proskaner-Elsner, Ueber die hygienische Untersuchung des Kohlebreiverfahrens zur Reinigung von $\mathrm{Abwässern} \mathrm{auf} \mathrm{der}$ KIärstation in Potsdam. Ebenda. S. 461.

${ }^{2}$ Babucke, Centralblatt für Bakteriologie. 1900. Bd. XXII u. XXIII. S. 800. 